\title{
Access to Higher Education in India: An Exploration of its Antecedents
}

\author{
Rakesh Basant \\ Gitanjali Sen
}

\author{
W.P. No. 2013-05-011 \\ May 2013
}

The main objective of the working paper series of the IIMA is to help faculty members, research staff and doctoral students to speedily share their research findings with professional colleagues and test their research findings at the pre-publication stage. IIMA is committed to maintain academic freedom. The opinion(s), view(s) and conclusion(s) expressed in the working paper are those of the authors and not that of IIMA.

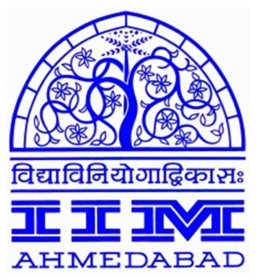

\section{INDIAN INSTITUTE OF MANAGEMENT \\ AHMEDABAD-380 015 \\ INDIA}




\title{
Access to Higher Education in India: An Exploration of Its Antecedents*
}

\author{
Rakesh Basant \\ Professor, Indian Institute of Management Ahmedabad \\ and Senior Fellow, Observer Research Foundation, Delhi, India \\ Email: rakesh@iimahd.ernet.in \\ Gitanjali Sen \\ Assistant Professor, School of Education, Shiv Nadar University, India
}

\begin{abstract}
Deficits in participation of marginalized groups in Higher Education (HE) have attracted significant policy and research attention. Recent studies have explored the role of socioreligious affiliation and other factors in determining participation in HE. It is also shown that appropriate measures of 'deficits' in participation should inform the nature and scope of affirmative action for marginalized groups. Using appropriate measures of participation, this paper explores if the role of socio-religious background and other factors has changed over a period of time. This dynamics of participation in HE is analyzed by using three rounds of NSS data for the period 1999-2010.
\end{abstract}

Keywords: Education, affirmative action, participation, caste, access, India

\footnotetext{
* This paper is a product of a larger research project entitled 'Pathfinder - Assessing the Impact of Higher Education Expansion on Economics Restructuring, Occupational Change and Access to Opportunities in Brazil and India' funded by the Economic and Social Research Council (ESRC), UK.
} 


\section{Access to Higher Education in India: An Exploration of Its Antecedents}

\section{Introduction}

The policy of affirmative action (AA), essentially in the form of reservation in jobs and higher education in the government sector has been in place in India for a long time but several issues remain unresolved. The two key unresolved issues relate to the factors that should inform the choice of beneficiary population and the duration for which AA benefits should continue. The discussion has also explored the possibility of bringing private sector under the ambit of AA policies. The 'reservation' debate has resurfaced with the inclusion of Other Backward Classes (OBC) for AA in Indian higher education. In an earlier paper, Basant and Sen (2010) argue that an appropriate measure of 'deficits' in participation among different 'socio-religious groups' should inform the nature and scope of affirmative action. In fact, the paper explores various determinants of participation in $\mathrm{HE}$ and suggests that 'deficits' in participation of higher education (HE) among some of the marginalized groups are not significant enough to suggest affirmative action in higher education for these groups. The present paper probes the determinants of HE completion rate further to analyze the changes over a period of time and robustness of the earlier argument. This is done by analyzing three rounds of NSS data during 1999-2000 to 2009-10.

The rest of the paper is organized in five sections. Section II provides a very brief historical account of the affirmative action policies in India. Section III discusses the relevant literature to provide a context to the empirical exploration in this paper. Section IV focuses on the research question of the present paper, along with the econometric model, research methodology and the data used. The empirical results and the key findings are presented in Section V. Finally, section VI concludes with a discussion of the policy implications of the empirical results.

\section{History of affirmative action in India}

India bears the legacy of extending privileges to the socially backwards castes from the very beginning of the states' formation. During the pre-independence movement, some concessions were extended to Dalits for bringing them into mainstream, through the so called 'Pune pact,' which came into operation through the Government of India Act, 1935 and later, became a part 
of the Indian constitution. Along with the effort of the Indian government through its constitutional powers, the southern states started making their own lists of backward classes for further upliftment of socially, educationally and economically backwards classes. The composite Madras state had a list of its own, which was followed by the state of Andhra Pradesh, after its formation. The same tradition was followed in Karnataka and then, extended to Bihar, Gujarat and other northern states much later.

Also educational support through scholarship schemes to the socially disadvantaged students has been in place from the beginning of five year plans. Apart from the assistance at the central level, several state governments have specific scholarship schemes for SC, STs and OBCs as well. More recently scholarships have been introduced for minorities by the central government.

\section{A brief review of available studies}

The participation in HE being strongly linked to completion of elementary, secondary and postsecondary education, a host of studies (NCERT: 1998, PROBE:1999, Pridmore:2007) discussing the educational gap at different levels lead us to the primary reasons behind educational deficits among socially disadvantageous groups at the college level. Sedwal and Kamat (2008) discuss the heterogeneous nature of the SCs and STs across states of India; the difference in intrinsic value of education among them, leading to lower participation at elementary level; and the issues of growing demand in some parts along with issues of access to education. However, in the context of higher education, the lower participation emerges both from the lack of demand arising from the facts discussed above, along with the presence of supply side constraints existing in Indian Higher Education (GoI: 2006 and 2007, Agarwal: 2006, Kaul:2006) as well as at the school level.

Basant and Sen (2010), shows that different measures of deficits do change the hierarchy of participation among different socio religious groups. Using the $61^{\text {st }}$ round of unemployment and employment survey data, probit estimates of participation of both the stock and flow measures indicate that an appropriate measure of deficit may change the debate around AA towards the issue of supply side constraints. 
Due to the paucity of panel data from a countrywide survey like the NSS, there are very few studies trying to compare education participation of socially disadvantageous groups over time. One such study by Azam and Blom (2008) compares the NSS data of rounds between 1993 to 2005, through statistical estimates of educational attainment, access, and transition to higher education across socially and economically disadvantaged groups. An interesting conclusion of their statistical analysis is that the variation across states in enrolment is largely due to variations in completion of higher secondary education. Moreover, deficits in transition rates between genders, between social groups, or between religious groups are much smaller than deficits in enrolment. The probit estimate of participation also supports the same results. However, hierarchy of participation in HE through the lenses of HE completion rate, and the dynamics of that over time in India across different socio-religious groups (henceforth, SRCs) are barely discussed in existing literature. This paper tries to fill in that gap.

\section{Research questions, methodology and data}

Two inter-related questions are explored here: (a) what is the role of SRC affiliation as determinant of participation in HE; and (b) how do the importance of these affiliations change over time, along with the change in hierarchy of participation. In order to explore the robustness of the hierarchy of participation in HE among different SRCs, this paper does a maximum likelihood estimate of a binary model of participation using the stock measure, where the dependent variable assumes a value of one if someone completed HE, else it takes a value of zero. This variable is again explained in section 5.1 later as the Current Generation Stock (CGS) measure. The focus of the paper being the dynamics of HE participation among different SRCs through a decade, the analysis has been conducted only with the stock model, for the sake of simplicity. Stock model has the advantage of estimating the rate of 'actual' completion of HE as compared to the flow model, where enrolment only gets estimated, and the dropouts are never accounted for. Although, the stock measures come with a 'historical burden,' a focus on a younger age cohort minimizes this problem.

To explore the socio religious status of individuals on participation in HE, the paper combines the caste and religious statuses to form seven SRCs: Hindu SC, Hindu ST, Hindu OBC, Hindu UC, Muslim OBC, Muslim General, and Other Minorities. In order to take care of the individual, household and location specific factors that could also influence participation in HE, the probit 
regression includes few more explanatory variables. At the individual level, age and sex of the person are included; and at household level, household size and logarithm of monthly household expenditure per capita are included. The state of residence is also controlled to take care of location specific factors. Since, the states of Jharkhand, Chhattisgarh, and Uttaranchal were created from the states of Bihar, Madhya Pradesh, and Uttar Pradesh, respectively in the year 2000 onwards; the former three states are kept with the parent state only for comparison across years.

Assuming determinants of participation to be different between urban and rural areas; and between full sample and eligible people sample, the model is estimated separately for all these four sub-samples. The eligibility is determined by whether the person has crossed the 'threshold' of higher secondary education and is eligible to participate in HE. Thus, this paper estimates a total of four specifications.

This study uses three rounds of Employment-Unemployment survey of the NSS data that are, the $55^{\text {th }}$ round collected in $1999-00$, the $61^{\text {st }}$ round collected in $2004-05$, and the $66^{\text {th }}$ round collected in 2009-10. All the data sets are household level survey data with detailed information on each member's demographic information such as age, sex, education, household size, and household level monthly expenditures.

\section{$5 \quad$ Empirical findings}

Using data from the three rounds of NSS, estimates of participation have been generated for three years.

\subsection{Participation in HE: broad trends}

The percentage of persons participating in HE among each of the seven SRCs, following both the stock and flow measures are presented in Table 1. The Current Generation Stock (CGS) measure includes all people between age 22 to 35 years, who have completed education of graduate and above level. The Current Generation Flow (CGF) model includes all persons in the age group 17-29 that are currently attending degree or diploma or higher level courses. (See Basant and Sen (2010) for a detailed discussion of various measures of participation). 
All different definitions of participation of the full sample indicate that, the participation increased in the year 2010 as compared to the 1999 for all SRCs. A more interesting result emerges from the eligible sample, where participation goes down for all SRCs in stock definitions, but goes up for all SRCs by CGF definitions, except for the Hindu ST. So the flow definition of participation indicates that completion of higher secondary education is an important policy tool to encourage higher enrolment in higher education, which does not guarantee higher completion though. However, the decline in participation among SRCs following the stock definitions may also be due to the base effect of increase in overall eligible population over the years as compared to the expansion of access to higher education.

Table 1: Share of each SRC in the relevant age group participating in HE

\begin{tabular}{|r|rrr|rrr|}
\hline & \multicolumn{2}{|c|}{ CGS: Full Sample(Age:22-35 yrs) } & \multicolumn{3}{|c|}{ CGF: Full Sample (Age: 17-29 yrs) } \\
\hline & $1999-00$ & $2004-05$ & $2009-10$ & $1999-00$ & $2004-05$ & $2009-10$ \\
\hline H-SC & 3.61 & 3.74 & 5.57 & 2.48 & 3.59 & 6.43 \\
H-ST & 2.11 & 2.34 & 3.53 & 2.97 & 3.42 & 4.23 \\
H-OBC & 5.22 & 6.39 & 9.62 & 3.49 & 5.00 & 10.38 \\
H-UC & 17.69 & 19.29 & 24.42 & 9.58 & 11.24 & 18.15 \\
M-OBC & 2.97 & 3.26 & 5.42 & 2.12 & 3.92 & 6.15 \\
M-G & 4.80 & 5.09 & 4.97 & 3.05 & 4.09 & 6.26 \\
OM & 12.40 & 11.89 & 16.12 & 8.04 & 8.00 & 13.64 \\
Total & 8.25 & 8.62 & 11.42 & 5.03 & 6.07 & 10.44 \\
& & & & & & \\
\hline & CGS: Eligible(Age: 22-35 yrs) & & CGF: Eligible (Age: 17-29 yrs) & \\
\hline H-SC & 52.81 & 43.67 & 49.1 & 32.29 & 32.25 & 42.81 \\
H-ST & 39.17 & 40.56 & 35.95 & 40.42 & 41.71 & 33.56 \\
H-OBC & 50.62 & 44.88 & 48.41 & 29.91 & 28.86 & 40.11 \\
H-UC & 64.65 & 58.50 & 59.4 & 33.80 & 31.55 & 41.05 \\
M-OBC & 48.89 & 40.94 & 48.36 & 29.20 & 36.09 & 40.55 \\
M-G & 54.66 & 51.17 & 44.58 & 32.88 & 35.40 & 43.46 \\
OM & 61.53 & 46.62 & 52.06 & 35.12 & 27.89 & 36.81 \\
Total & 58.68 & 51.04 & 52.71 & 32.97 & 31.13 & 40.42 \\
& & & & & \\
\hline
\end{tabular}

Figures $1 \mathrm{a}, 1 \mathrm{~b}$ and $1 \mathrm{c}$ indicate that participation in higher education has increased consistently among all age groups over the last decade. The highest incremental supply in graduate courses has originated from the 18-24 age group, followed by the 25-29 age group. 


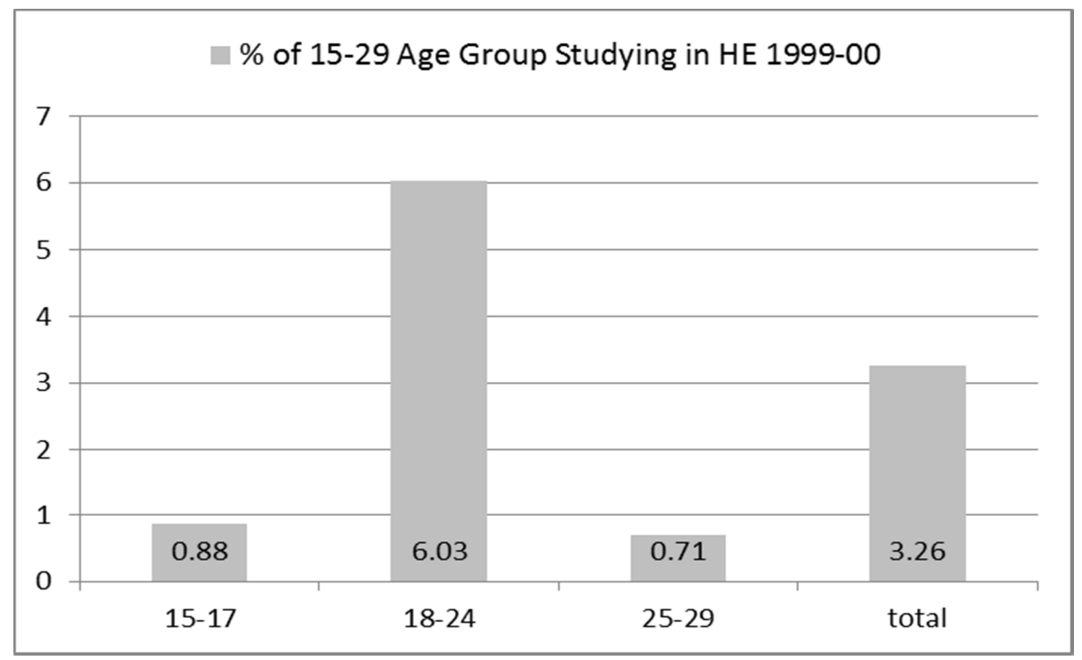

Figure1a

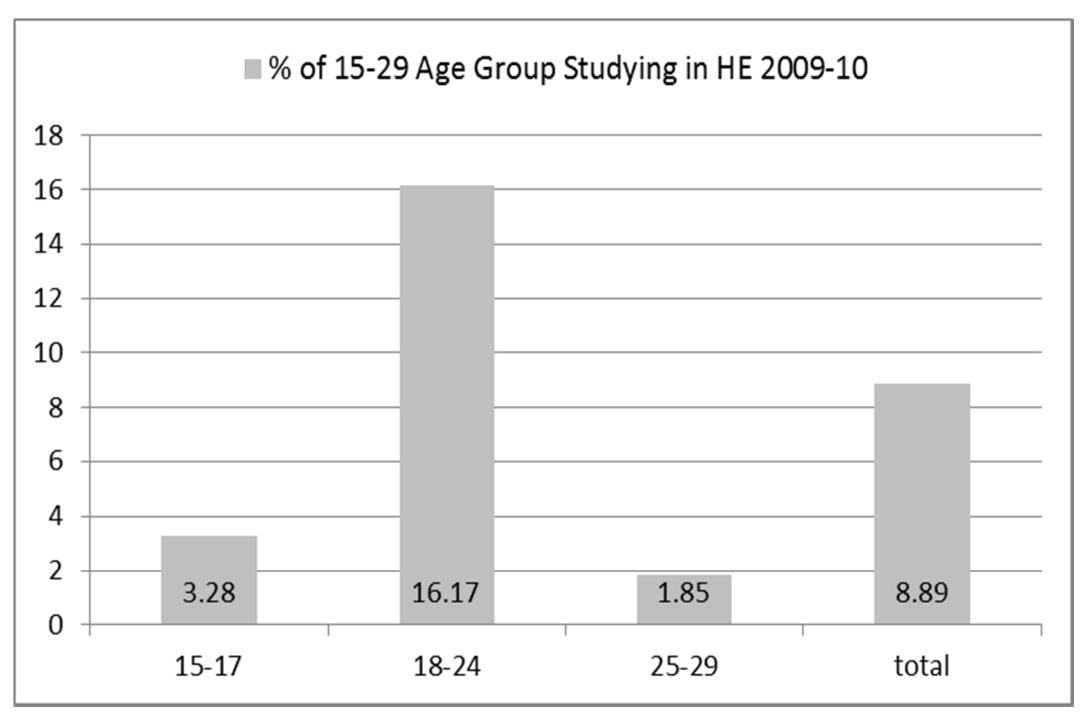

Figure 1c

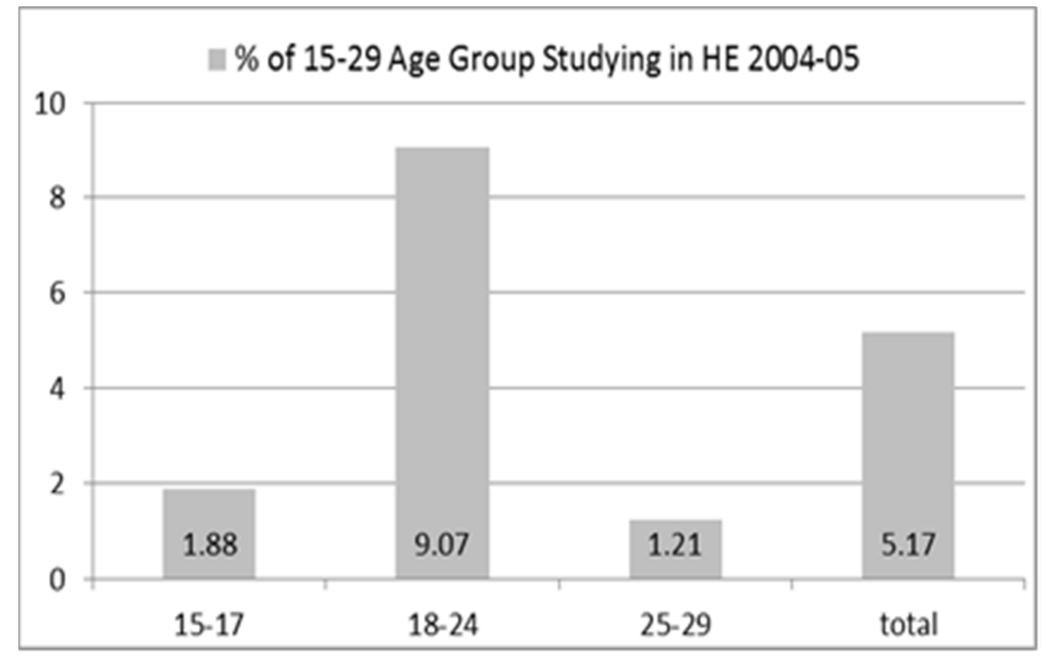

Figure 1b 


\subsection{Participation in education at different levels and transition to eligibility for $\mathrm{HE}$}

Tables $2 \mathrm{a}, 2 \mathrm{~b}, 2 \mathrm{c}$ provide a comparative analysis of participation in education at different age groups and changes in them over time. It also provides estimates of the percentage of population progressing to HE during the decade of 1999-2010. Here, while one can notice overall increase in participation in education for all age groups over the years, the highest increase can be seen for age group 7-14, probably an effect of the countrywide Sarva Siksha Abhiyan (Education for all) ${ }^{i}$ programme. There has been some increase in out of school population of age 25-29 between 2004-2010, primarily due to a drop in participation in secondary, higher secondary or HE of the 15-17 and 18-24 age groups between 2004 and 2010. However, the HE participation of age group 25-29 years has increased consistently during this period, along with total participation of all age groups together.

Table 2a: Share of population studying at different levels - by age groups: 1999-00

\begin{tabular}{|l|r|r|r|r|r|r|}
\hline $\begin{array}{l}\text { Age: } \\
\text { below 30 years }\end{array}$ & $0-6$ & $7-14$ & $15-17$ & $18-24$ & $25-29$ & Total \\
\hline EGS/NFEC/AEC/TLC & 0.38 & 0.18 & 0.07 & 0.07 & 0.05 & 0.11 \\
Pre-primary (nursery, Kindergarten) & 10.47 & 9.15 & 0.39 & 0.07 & 0.03 & 0.15 \\
Primary (class I to IV / V ) & 12.15 & 39.77 & 1.88 & 0.2 & 0.08 & 0.4 \\
Middle & 0.18 & 23.14 & 10.87 & 0.76 & 0.14 & 0.43 \\
Secondary and higher secondary & 0.01 & 4.85 & 36.11 & 6.72 & 0.29 & 0.74 \\
Graduate \& above & 0 & 0 & 0.98 & 6.21 & 0.76 & 0.64 \\
Diploma/certificate: below/above & 0 & 0 & 0.47 & 2.17 & 0.39 & 0.27 \\
graduate & & & & & & \\
\hline Total in school & 23.19 & 77.09 & 50.77 & 16.21 & 1.75 & 2.74 \\
\hline Total Out of school & 76.8 & 22.91 & 49.23 & 83.79 & 98.25 & 97.26 \\
\hline Total & 100 & 100 & 100 & 100 & 100 & 100 \\
\hline
\end{tabular}

Table 2b: Share of population studying at different levels - by age groups: 2004-05

\begin{tabular}{|l|r|r|r|r|r|r|}
\hline Age: & $0-6$ & $7-14$ & $15-17$ & $18-24$ & $25-29$ & Total \\
below 30 years & & & & & & \\
\hline EGS/NFEC/AEC/TLC & 0.45 & 0.16 & 0.04 & 0.01 & 0 & 0.17 \\
Pre-primary (nursery, Kindergarten) & 9.09 & 0.94 & 0.01 & 0.01 & 0.01 & 2.58 \\
Primary (class I to IV / V ) & 19.38 & 50.16 & 1.67 & 0.1 & 0.12 & 20.51 \\
Middle & 0.14 & 26.53 & 9.51 & 0.54 & 0.06 & 9.24 \\
Secondary and higher secondary & 0 & 8.15 & 41.63 & 6.3 & 0.21 & 7.93 \\
Graduate \& above & 0 & 0 & 1.73 & 7.94 & 0.80 & 1.96 \\
Diploma/certificate: below graduate & 0 & 0 & 0.68 & 1.59 & 0.23 & 0.44 \\
Diploma/certificate: graduate \& above & 0 & 0 & 0.15 & 1.13 & 0.42 & 0.31 \\
\hline Total in school & 29.06 & 85.94 & 55.42 & 17.62 & 1.85 & 43.14 \\
\hline Total Out of school & 70.94 & 14.06 & 44.58 & 82.38 & 98.15 & 56.86 \\
\hline Total & 100 & 100 & 100 & 100 & 100 & 100 \\
\hline
\end{tabular}


Table 2c: Share of population studying at different levels - by age groups: 2009-10

\begin{tabular}{|l|r|r|r|r|r|}
\hline Age: & $7-14$ & $15-17$ & $18-24$ & $25-29$ & Total \\
between 7 to 29 years & & & & & \\
\hline EGS/NFEC/AEC/TLC & 0.11 & 0.04 & 0.02 & 0.00 & 0.04 \\
Pre-primary (nursery, Kindergarten) & 1.05 & 0.02 & 0.00 & 0.03 & 042 \\
Primary (class I to IV / V ) & 48.6 & 1.08 & 0.14 & 0.08 & 19.11 \\
Middle & 30.39 & 6.72 & 0.40 & 0.24 & 12.91 \\
Secondary & 11.43 & 30.15 & 1.60 & 0.15 & 9.08 \\
Higher secondary & 0.37 & 26.58 & 5.75 & 0.19 & 5.49 \\
Graduate \& above & 0 & 3.04 & 13.93 & 1.30 & 4.65 \\
Diploma/certificate: below graduate & 0 & 0.24 & 2.25 & 0.54 & 0.79 \\
Diploma/certificate: graduate \& above & 0 & 0.47 & 1.95 & 0.16 & 0.65 \\
& & & & & \\
\hline Total in school & 91.95 & 68.34 & 26.04 & 2.69 & 53.14 \\
\hline Total Out of school & 8.05 & 31.66 & 73.96 & 97.31 & 46.86 \\
\hline Total & 100 & 100 & 100 & 100 & 100 \\
\hline
\end{tabular}

Note: Current education question is asked to people between 5 and 29 years of age. Hence we removed the first age group to maintain consistency across years.

\subsection{Participation in education by SRCs}

Table 3 provides a comparative picture of participation at different levels of education by different SRCs. Overall, the share of out of school children has consistently declined between the period 1999 and 2010 for all. This share reached its peak among Muslim OBC in the year 1999, but declined thereafter. The participation of Hindu OBC in HE (combining degree and diploma courses) has increased sharply between 1999 and 2010, along with almost all other SRCs, except for Muslim general. The latter's participation in HE has increased at a much slower rate.

Table 3: Percentage of currently studying population at different levels by SRC

\begin{tabular}{|c|c|c|c|c|c|c|c|c|}
\hline Year & Currently Studying or not:Age 18-24 & HSC & HST & HOBC & HUC & MOBC & MGEN & OM \\
\hline \multirow{8}{*}{$\begin{array}{l}\text { ஓ } \\
\stackrel{1}{ } \\
\text { } \\
\text { જ }\end{array}$} & Not attending & 88.79 & 89.66 & 87.52 & 73.23 & 92 & 87.78 & 76.08 \\
\hline & EGS/NFEC/AEC/TLC & 1 & 0.09 & 0.07 & 0.02 & 0.02 & 0.1 & 0.03 \\
\hline & Pre-primary (nursery, Kindergarten) & 0.06 & 0.07 & 0.09 & 0.02 & 0.01 & 0.18 & 0.05 \\
\hline & Primary (class I to IV / V ) & 0.17 & 0.04 & 0.19 & 0.33 & 0.04 & 0.19 & 0.11 \\
\hline & Middle & 0.88 & 0.55 & 0.68 & 0.69 & 0.8 & 1.05 & 1.01 \\
\hline & Secondary and higher secondary & 5.68 & 4.38 & 5.62 & 9.81 & 3.4 & 5.69 & 8.87 \\
\hline & Graduate $\&$ above & 3.16 & 4.23 & 4.31 & 11.95 & 2.51 & 3.45 & 9.67 \\
\hline & $\begin{array}{l}\text { Diploma/certificate: below \& above } \\
\text { graduate }\end{array}$ & 1.17 & 0.99 & 1.51 & 3.93 & 1.2 & 1.57 & 4.17 \\
\hline \multirow{9}{*}{$\begin{array}{l}n \\
0 \\
\dot{1} \\
\delta \\
8\end{array}$} & Not attending & 87.35 & 88.5 & 84.49 & 71.63 & 88.51 & 85.6 & 76 \\
\hline & EGS/NFEC/AEC/TLC & 0.01 & 0 & 0 & 0.03 & 0.08 & 0.01 & 0 \\
\hline & Pre-primary (nursery, Kindergarten) & 0.03 & 0 & 0.01 & 0 & 0.02 & 0 & 0 \\
\hline & Primary (class I to IV / V ) & 0.16 & 0.12 & 0.06 & 0.06 & 0.26 & 0.2 & 0.08 \\
\hline & Middle & 0.66 & 0.59 & 0.45 & 0.48 & 0.47 & 0.67 & 0.66 \\
\hline & Secondary and higher secondary & 5.43 & 4.88 & 5.97 & 7.9 & 3.91 & 6.61 & 8.53 \\
\hline & Graduate \& above & 4.36 & 4.75 & 6.63 & 15.21 & 5.16 & 5.44 & 10.1 \\
\hline & Diploma/certificate: below graduate & 1.19 & 0.74 & 1.53 & 2.44 & 0.99 & 0.76 & 2.95 \\
\hline & Diploma/certificate: graduate \& above & 0.81 & 0.42 & 0.86 & 2.25 & 0.6 & 0.68 & 1.69 \\
\hline
\end{tabular}




\begin{tabular}{|l|l|l|l|l|l|l|l|l|}
\hline & Not attending & 81.35 & 84.03 & 73.71 & 61.34 & 82.79 & 81.42 & 64.94 \\
& EGS/NFEC/AEC/TLC & 0.00 & & 0.01 & 0.00 & 0.00 & 0.11 & 0 \\
& Pre-primary (nursery, Kindergarten) & 0.00 & & 0.01 & 0.00 & 0.01 & 0.00 & 0.01 \\
$\frac{0}{\delta}$ & Primary (class I to IV / V ) & 0.19 & 0.02 & 0.09 & 0.17 & 0.27 & 0.26 & 0.01 \\
$\delta$ & Middle & 0.47 & 0.54 & 0.45 & 0.07 & 0.36 & 0.76 & 0.43 \\
& Secondary & 2.00 & 1.5 & 1.64 & 1.23 & 1.64 & 1.52 & 1.61 \\
& Higher Secondary & 4.70 & 5.54 & 5.89 & 6.38 & 4.76 & 5.17 & 8.23 \\
& Graduate and above & 9.10 & 6.42 & 14.49 & 23.24 & 7.56 & 8.39 & 16.33 \\
& Diploma/certificate: below graduate & 1.06 & 0.49 & 1.8 & 4.82 & 1.11 & 1.42 & 3.71 \\
& Diploma/certificate: graduate \& above & 1.13 & 1.46 & 1.91 & 2.75 & 1.50 & 0.95 & 4.73 \\
\hline
\end{tabular}

\subsection{Correlates of $\mathrm{HE}$}

Apart from the SRC status, a variety of factors can affect participation in HE. Table 4 provides few statistics of eligible population for HE with respect to different individual and household characteristics. Each row of the table represents the percentage among respective group of population above 17 years age, who completed higher secondary education. The estimates indicate that the supply of eligible population for higher education has increased over the years for both the genders, all SRCs, and among both rural and urban persons. While the increase in participation seems to be different across SRCs over the years, one is not able to say anything concrete about these differential trends because one is not very sure about the growth of population share among these SRCs during the period under consideration.

Table 4: Share of higher secondary completed above 17 years age among each group -Individual and Family Characteristics

\begin{tabular}{|l|l|l|l|}
\hline Among the following sample of above 17 years age & \multicolumn{3}{l|}{$\begin{array}{l}\text { Percentage Completed Higher } \\
\text { Secondary }\end{array}$} \\
\hline Individual Characteristics & $1999-00$ & $2004-05$ & $2009-10$ \\
\hline Male & 14.63 & 17.37 & 21.75 \\
Female & 7.46 & 9.63 & 13.39 \\
\hline Hindu SC & 4.93 & 6.49 & 9.44 \\
Hindu ST & 4.35 & 4.64 & 7.98 \\
Hindu OBC & 7.47 & 10.69 & 15.27 \\
Hindu UC & 21.99 & 26.99 & 32.83 \\
Muslim OBC & 4.92 & 6.89 & 9.41 \\
Muslim general & 7.12 & 8.5 & 10.63 \\
Other minorities & 15.50 & 19.56 & 24.08 \\
\hline Rural & 6.03 & 7.86 & 10.71 \\
Urban & 24.69 & 28.49 & 34.36 \\
\hline
\end{tabular}

\subsection{Antecedents of participation in HE: results of the econometric analysis}

Marginal effects, calculated at the mean of all the variables, from four specifications of probit model, run separately for all three years are presented in table 5. Throughout this analysis we use the terms 'participation in HE' and 'completion of HE' interchangeably, as the stock measure of HE participation used in this analysis includes people between the age 22-35 years, who have completed some kind of degree or diploma of undergraduate or above level. 
Table 5: Marginal effects in Stock model- on completing HE: age 22-35

\begin{tabular}{|c|c|c|c|c|c|c|}
\hline & \multicolumn{3}{|c|}{ Stock Urban Full Sample } & \multicolumn{3}{|c|}{ Stock Urban Eligible Sample } \\
\hline Variables & 1999-00 & 2004-05 & $2009-10$ & 1999-00 & $2004-05$ & $2009-10$ \\
\hline Age & $0.00 * * *$ & $-0.00 * * *$ & $0.00 * * *$ & $0.01 * * *$ & -0.00 & $0.00 * *$ \\
\hline Hindu ST & 0.02 & 0.03 & 0.00 & -0.02 & 0.02 & -0.04 \\
\hline Hindu OBC & $0.03 * * *$ & $0.04 * * *$ & $0.02 *$ & -0.02 & 0.01 & -0.03 \\
\hline Hindu UC & $0.15 * * *$ & $0.14 * * *$ & $0.13 * * *$ & $0.06 * * *$ & $0.09 * * *$ & $0.04 *$ \\
\hline Mus OBC & $-0.06 * * *$ & $-0.05 * * *$ & $-0.09 * * *$ & $-0.11 * *$ & -0.01 & -0.08 \\
\hline Mus Gen & 0.00 & 0.01 & $-0.08 * * *$ & -0.03 & 0.02 & $-0.11 * * *$ \\
\hline $\mathrm{OM}$ & $0.14 * * *$ & $0.11 * * *$ & $0.13 * * *$ & 0.04 & 0.05 & 0.04 \\
\hline Male & $0.05 * * *$ & $0.03 * * *$ & $0.02 * *$ & 0.02 & $-0.04 * * *$ & $-0.02 *$ \\
\hline Log MPCE & $0.27 * * *$ & $0.26 * * *$ & $0.33 * * *$ & $0.24 * * *$ & $0.21 * * *$ & $0.25 * * *$ \\
\hline Hh Size & $0.01 * * *$ & $-0.03 * * *$ & $0.02 * * *$ & $0.01 * * *$ & $-0.03 * * *$ & $0.02 * * *$ \\
\hline Observed P & 0.19 & 0.20 & 0.25 & 0.67 & 0.59 & 0.62 \\
\hline Predicted P & 0.13 & 0.14 & 0.19 & 0.68 & 0.60 & 0.63 \\
\hline No. of Obs & 55601 & 50102 & 43967 & 17347 & 15711 & 17282 \\
\hline Waldchi2(36) & 4613.9 & 2366.7 & 2291 & 620.2 & 409.1 & 581.0 \\
\hline Prob $>$ chi 2 & 0 & 0 & 0 & 0 & 0 & 0 \\
\hline Log Pseudo L & -20833 & -19171 & -18803 & -10329 & -10059 & -10573 \\
\hline \multirow[t]{2}{*}{ Pseudo R2 } & 0.24 & 0.23 & 0.24 & 0.06 & 0.05 & 0.08 \\
\hline & \multicolumn{3}{|c|}{ Stock Rural Full Sample } & \multicolumn{3}{|c|}{ Stock Rural Eligible Sample } \\
\hline Age & $0.00 * * *$ & $-0.00 * * *$ & $0.00 * * *$ & $0.01 * * *$ & $0.00^{*}$ & 0.00 \\
\hline Hindu ST & $-0.01 * * *$ & $-0.01 * *$ & 0.00 & $-0.16^{* * *}$ & -0.04 & -0.13 \\
\hline Hindu OBC & $0.00 *$ & -0.00 & $0.00 * * *$ & $-0.10 * * *$ & $-0.04 *$ & -0.03 \\
\hline Hindu UC & $0.02 * * *$ & $0.02 * * *$ & $0.01 * * *$ & 0.00 & 0.03 & 0.02 \\
\hline Mus OBC & $-0.01 * * *$ & $-0.01 * * *$ & $0.01 * *$ & -0.07 & -0.07 & 0.02 \\
\hline Mus Gen & $-0.01 * *$ & $-0.01 * * *$ & 0.00 & -0.02 & 0.00 & -0.03 \\
\hline $\mathrm{OM}$ & 0.00 & 0.00 & 0.01 & $-0.09 * *$ & -0.04 & -0.05 \\
\hline Male & $0.03 * * *$ & $0.03 * * *$ & $0.00 * * *$ & $0.06 * * *$ & $0.04 * * *$ & 0.01 \\
\hline Log MPCE & $0.05 * * *$ & $0.06 * * *$ & $0.00 * * *$ & $0.16 * * *$ & $0.19 * * *$ & $0.14 * * *$ \\
\hline Hh Size & $0.00 * * *$ & $-0.01 * * *$ & $0.00 * * *$ & $0.00 * *$ & $-0.02 * * *$ & $0.01 * * *$ \\
\hline Observed P & 0.04 & 0.04 & 0.06 & 0.48 & 0.41 & 0.41 \\
\hline Predicted P & 0.02 & 0.02 & 0.03 & 0.48 & 0.41 & 0.41 \\
\hline No. of Obs & 84428 & 89911 & 64785 & 9254 & 13703 & 13483 \\
\hline Waldchi2(36) & 2634.4 & 3089.3 & 1717.2 & 356.8 & 327.2 & 221.4 \\
\hline Prob $>$ chi 2 & 0 & 0 & 0 & 0 & 0 & 0 \\
\hline Log Pseudo L & -11805 & -13060 & -11676 & -6044 & -8908 & -8750 \\
\hline Pseudo R2 & 0.18 & 0.18 & 0.17 & 0.06 & 0.04 & 0.04 \\
\hline
\end{tabular}

Note: $* * *_{-}-1 \%$ level of significance, $* *-5 \%$ level of significance, $*_{-}-10 \%$ level of significance.

The results for state dummies are not reported here due to limited space. 
The lack of statistical significance of Hindu ST in urban areas as presented in the first six columns of the upper panel may stem from the fact that most Hindu ST population stay in rural areas, leading to relatively less variation in that variable in urban areas. In rural areas, Hindu ST seem to have lower chances of participation as compared to Hindu SC, ceteris paribus; and that chance has been as low as sixteen percentage points among rural eligible population in the year 1999-00. However, in the next two years of study, Hindu SC may not have higher chances of participation than Hindu ST as the marginal effects are not statistically significant.

Hindu $\mathrm{OBCs}$ are more likely to complete $\mathrm{HE}$ as compared to Hindu SC in full sample with stronger effects in urban areas. But among eligible population, Hindu OBCs seem to have lower chances of participation, particularly in rural areas. However, the lack of statistical significance among eligibles in recent years indicates that Hindu SCs seem to have lost that advantage over Hindu OBCs in recent years, after both cross the threshold of higher secondary education. Being eligible seems to be the key criteria in difference in HE participation between these two groups, and there seem to be less variation among these eligible groups in recent years.

Hindu upper castes are more likely to complete HE in urban areas as compared to Hindu SC, for all the years under study. However, that advantage reduces to as low as four percentage points in 2009-10 for the urban eligible, as compared to thirteen percentage points among urban full sample in the same year. So, here too, crossing the threshold of eligibility has always been the key criteria for the difference between these two groups in HE participation. The picture looks quite similar in rural areas, where the marginal effects are statistically significant in full sample, but lose the statistical significance among eligible sample. Again, it may stem from the fact that once rural Hindu UCs cross the threshold of higher secondary education, not much variation is left with the variable. However, over all, the marginal effects in rural areas have always been less than the ones in urban areas for the otherwise same model specification. This may indicate the lack of accessibility of institutes of higher education in rural areas, which may have prevented all from participation in HE in general. 
Muslim OBCs have lower chances of HE participation as compared to Hindu SCs in urban areas through all the years of study. However, the advantage of Hindu SCs over Muslim OBCs seems to have reduced in recent years under study among both urban and rural eligible, which again indicate the eligibility for entering into HE to be the key factor for completion of HE. Another interesting fact to be noticed in rural full samples is that, the one percentage point of lower chance of HE participation of Muslim OBCs over Hindu SCs has turned into one percentage point of higher chance among the former in the most recent year. This was never the case in any specification of urban area, and is a typical case of Muslims in rural areas only, where they seem to be in better condition.

The above story of rural-urban divide among Muslims prevails among Muslim general population too. Muslim generals seem to have eight percentage point lower chances of participation among urban full sample and eleven percentage point lower chances in urban eligible sample, as compared to Hindu SC in most recent year. The fact to be noticed here is, after crossing the threshold of higher secondary education the chances of participation even lowers among urban Muslims as compared to Hindu SCs. It may again stem from the general condition of urban Muslims, where the way Hindu SCs can take advantage of crossing the threshold of higher education, urban Muslims are probably unable to take that advantage. However, this is not the case in rural areas, where being eligible for HE actually reduces the statistical significance of the marginal effects in all three years of study.

For other minorities again, an eleven to fourteen percentage point of higher chances of HE participation as compared to Hindu SCs, in urban areas for all the three years, seem to obliterate once both cross the threshold of higher secondary education, as all the marginal effects lose statistical significance. In full sample of rural areas, neither of the groups seems to have higher chances of participation over the other; but among eligible population, Hindu SCs may have slightly higher chances, which again seems to have disappeared in recent years.

Among other correlates of HE in table 5, negative signs of marginal effects for men in the urban eligible area indicate two interesting facts. First, once the threshold of higher secondary education is crossed, urban women have higher chances of completing HE than their male counterparts. This may indicate the effect of better access to educational institutions in urban 
areas. Second, the absence of same sign in rural areas may indicate the importance of educational access in rural areas as a strong determinant in completion of HE. One more reason for lower prospects of men's participation among urban eligibles may be due to the nature of urban job market, where availability of low-skilled jobs can accommodate higher secondary educated males. Otherwise, the difference in probability of participation between male and female has reduced over the years.

Increase in age by one year for an average person does not affect chances of participation in any specification of the model. Higher income, as proxied by per capita expenditures always indicate higher participation in HE, but that effect is significantly less in rural full sample. This may again strengthen the accessibility issue of secondary and higher secondary institutions in rural areas. The comparatively higher effects of expenditure variables among rural eligibles indicate that once someone crosses the threshold of higher secondary education, then higher per capita income may influence higher participation; but till then, per capita income has very small effect. The latter may be due to unavailability of enough secondary or higher secondary institutions in rural areas. Having one additional member in the family actually increases chances of $\mathrm{HE}$ participation in the years 1999-00 and 2009-10, but decreases chances during the year 2004-05. Whether that is due to the scale effect only, or due to some other unobserved factors, is outside the scope of this study.

In order to capture the dynamics of hierarchy of participation amongst SRCs over the decade under study, we rank the SRCs according to their marginal effects, and irrespective of their statistical significance in figures $2 \mathrm{a}, 2 \mathrm{~b}, 2 \mathrm{c}, 2 \mathrm{~d}$. 


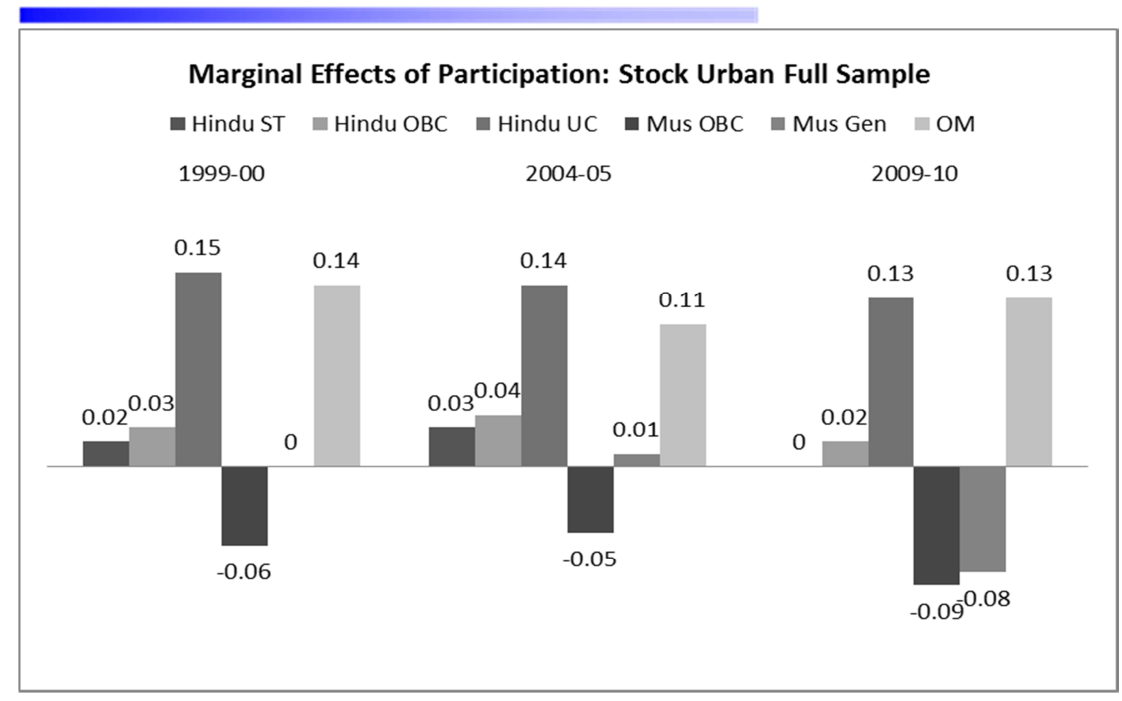

Figure 2a

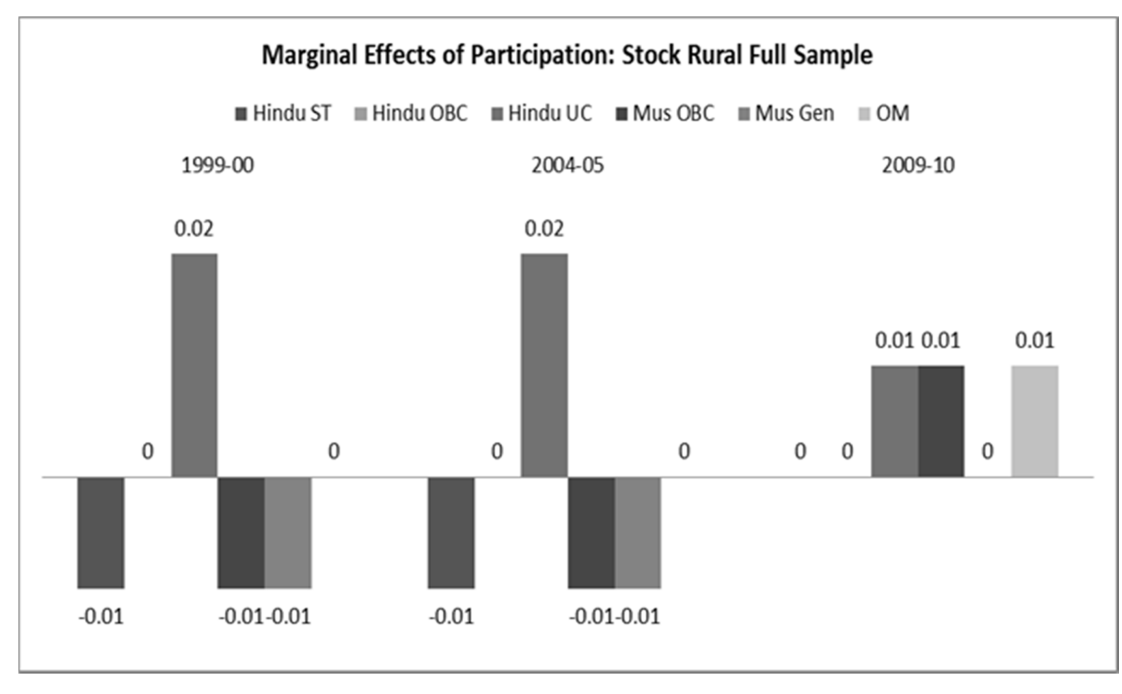

Figure 2c
Marginal Effects of Participation: Stock Urban Eligible Sample

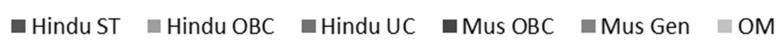

1999-00

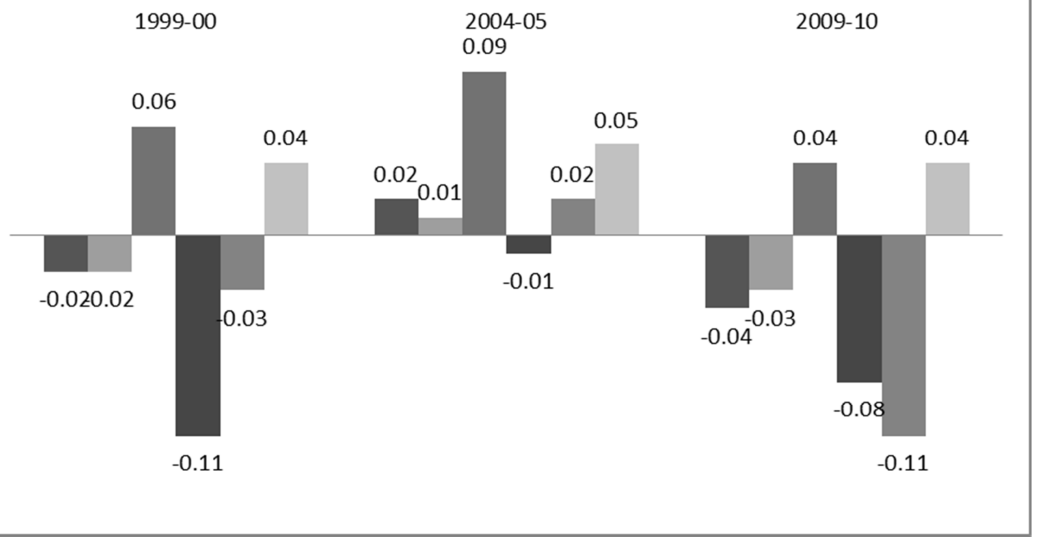

2009-10

Figure $2 b$

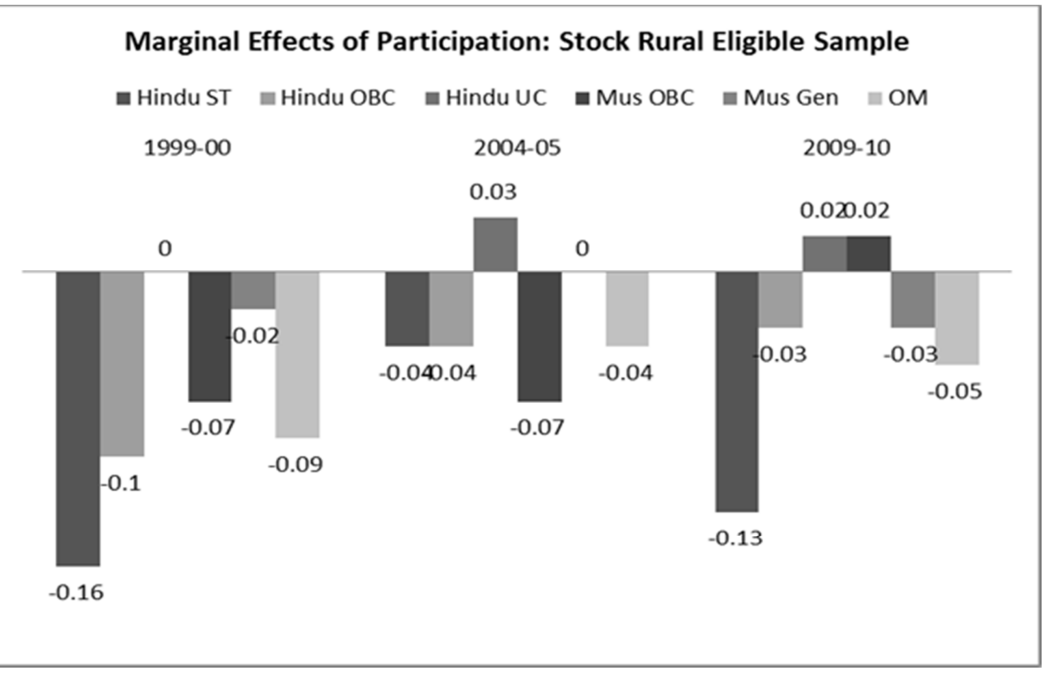

Figure 2d 
The hierarchies do not seem to change much over years in full sample of urban population, but seem to change among eligible samples, or in rural areas. This may again indicate the importance of access to educational institutions in rural area and crossing the threshold of higher secondary education as two important factor contributing to higher participation in HE.

\subsection{Exploring the role of supply side variables}

In order to check the access to schools issue that might affect eligibility, we have used the $64.25^{\text {th }}$ round of NSS data, which provides detailed household level information on educational expenditures and related issues. Along with household and individual level details used in this present study, the 64.25th round of data also includes details on distance to secondary schools, which could be the closest proxy for access to school. Specifications of all models remaining the same as earlier, we include the dummy variable equals to zero if distance to secondary school is less than $2 \mathrm{kms}$ and equal to one if it is more than $2 \mathrm{kms}$ in the new specification. One expects a negative sign for the marginal effects of this variable if distance to secondary school has any effect on completion of HE. The results presented in table 6 provide us the same sign, indicating further the importance of access to secondary school even for encouraging higher participation in HE. The fact that marginal effects of all other variables remains same indicate that distance to secondary school is not related to one's socio-religious affiliation within this specific model. 
Table 6: Stock Model of $64.25^{\text {th }}$ Round: Probability of Current Participation - Controlling for Access

\begin{tabular}{|c|c|c|c|c|c|c|c|c|}
\hline \multirow{3}{*}{$\begin{array}{l}\text { Completed } \\
\text { graduate or not } \\
\text { Variables }\end{array}$} & \multicolumn{4}{|c|}{ Marginal effects $(\mathrm{dF} / \mathrm{dx})$ : Urban } & \multicolumn{4}{|c|}{ Marginal effects $(\mathrm{dF} / \mathrm{dx})$ : Rural } \\
\hline & \multicolumn{2}{|c|}{ Full Sample } & \multicolumn{2}{|c|}{ Eligible Sample } & \multicolumn{2}{|c|}{ Full Sample } & \multicolumn{2}{|c|}{ Eligible Sample } \\
\hline & Spec1 & Spec 2 & Spec1 & Spec 2 & Spec1 & Spec 2 & Spec1 & Spec 2 \\
\hline Age & $0.00 * * *$ & $0.00 * * *$ & $0.00 * * *$ & $0.00 * * *$ & $0.00 * * *$ & $0.00 * * *$ & 0.05 & $0.00 * * *$ \\
\hline Hindu ST & 0.02 & 0.02 & 0.04 & 0.04 & 0.00 & 0.00 & -0.01 & 0.01 \\
\hline Hindu OBC & $0.03 * * *$ & $0.03 * * *$ & 0.01 & 0.01 & $0.00 * *$ & $0.00^{* *}$ & $-0.04 *$ & 0.00 \\
\hline Hindu UC & $0.14 * * *$ & $0.14 * * *$ & $0.10 * * *$ & $0.10 * * *$ & $0.04 * * *$ & $0.04 * * *$ & -0.05 & $0.05^{* *}$ \\
\hline Mus OBC & $-0.07 * * *$ & $-0.07 * * *$ & -0.04 & -0.04 & $-0.02 * * *$ & $-0.02 * * *$ & 0.00 & -0.03 \\
\hline Mus Gen & $-0.03 * * *$ & $-0.03 * * *$ & 0.00 & 0.00 & $-0.01 * *$ & $-0.01 * *$ & 0.02 & 0.04 \\
\hline OM & $0.08 * * * *$ & $0.08 * * *$ & 0.02 & 0.02 & 0.00 & 0.00 & $0.05 * * *$ & -0.04 \\
\hline Male & $0.02 * * *$ & $0.02 * * *$ & $-0.05 * * *$ & $-0.05^{* * *}$ & $0.02 * *$ & $0.02 * * *$ & $0.15^{* * *}$ & 0.00 \\
\hline Log MPCE & $0.29 * * *$ & $0.29 * * *$ & $0.24 * * *$ & $0.24 * * *$ & $0.06 * * *$ & $0.06 * * *$ & 0.00 & $0.18 * * *$ \\
\hline $\begin{array}{l}\text { Hh Size } \\
\text { Distance School }\end{array}$ & $0.01 * * *$ & $\begin{array}{l}0.01 * * * \\
-0.02 * *\end{array}$ & $0.01 * * *$ & $\begin{array}{l}0.01 * * * \\
-0.02\end{array}$ & $0.00 * * *$ & $\begin{array}{l}0.00 * * * \\
-0.01 * * *\end{array}$ & & $\begin{array}{l}0.01 * * \\
-0.04 * * *\end{array}$ \\
\hline Observed P & 0.21 & 0.21 & 0.61 & 0.61 & 0.05 & 0.05 & 0.31 & 0.42 \\
\hline Predicted P & 0.16 & 0.16 & 0.62 & 0.62 & 0.03 & 0.03 & 0.26 & 0.41 \\
\hline No. of Obs & 42215 & 42141 & 14460 & 14436 & 70773 & 70382 & 8018 & 8060 \\
\hline Waldchi2(36) & 3275 & 3277.73 & 593.6 & 597.44 & 1904.9 & 2069.53 & 807.6 & 292.01 \\
\hline Prob > chi 2 & 0 & 0 & 0 & & 0 & 0 & & 0 \\
\hline Log Pseudo L & -16866 & -16831.5 & -8986 & -8969.88 & -11014 & -10909.1 & -4012 & -5249.99 \\
\hline Pseudo R2 & 0.22 & 0.22 & 0.07 & 0.07 & 0.16 & 0.16 & 0.19 & 0.04 \\
\hline
\end{tabular}

Note: $* * *_{-} 1 \%$ level of significance, $* *-5 \%$ level of significance, $*_{-}-10 \%$ level of significance.

The results for state dummies are not reported here due to limited space. 


\section{Conclusion}

A few issues emerged from our earlier analysis of the NSS data (Basant and Sen, 2010). One related to the linkage between affirmative action as practiced by policies of reservation in India and the levels of participation in HE. We had asked the question if such action be linked to deficits of respective groups. If yes, what type of deficits one should go by? For example, our data showed that the deficits for Hindu OBC are not very high, particularly when one looks at the eligible population. This has been substantiated by additional data from two more rounds. Moreover, econometric analysis of the data showed that once other factors are controlled for, while difference in probability of participation with Hindu SC declines dramatically for most groups, the 'hierarchy of deprivation' is not entirely clear. The results of this paper have further corroborated that finding. This adds to the argument that a better understanding of the 'hierarchy of deprivation' may be critical for a more nuanced policy of affirmative action, including reservation.

Secondly, our earlier results raised questions about how in the discussion on higher education, should one deal with the issue of eligibility. Deficits for the under-privileged were found to be significantly lower among the eligible population, even after we control for a variety of other factors. Thus, once persons from under privileged groups cross the school threshold, the chances of them going to college are quite high. Once again, the results of data from other rounds corroborate these empirical conclusions. The importance of the additional control for access to secondary school also supports the argument. Clearly, a better understanding of the constraints on school education is critical if participation in higher education is to be enhanced. Therefore, should the higher education policy also focus on ensuring that the threshold is crossed? Arguably, reservation in higher education is an incentive to cross the threshold. Similarly, one can argue that job reservation can enhance the incentives to participate in higher education. Are these adequate? To what extent have these worked? Do we have better options for affirmative action? Do the reservation policies need to be revised frequently along with being more dynamic to reflect the change in participation among eligible underprivileged?

Thirdly, the results reported here once again raise questions about the efficacy of socio-religious affiliation to be the sole focus of affirmative action. Since many factors, other than socio- 
religious affiliation also influence participation in a significant manner, an exclusive focus on such affiliation for affirmative action seems inappropriate. The importance of economic background as well as that of location highlights the role of the supply side factors in affecting the participation of various groups. Unfortunately, we were not able to explore the role of supply side factors here. The data limitations constrained our analysis but it may be useful in subsequent analyses to further explore the interaction effects between socio-religious affiliation and other explanatory factors, including the availability of higher secondary schools and HE institutions in the vicinity.

\section{Reference}

Agarwal, P. 2006. "Higher education in India: The need for change," working paper 180, Indian Council for Research on International Economic Relations, New Delhi.

Azam, Mehtabul and Andreas Blom. 2008. "Progress in Participation in Tertiary

Education in India from 1983 to 2004," Policy Research working paper 4793, Human Development Department, The World Bank, South Asia Region, December.

Basant, Rakesh and Gitanjali Sen. 2010. "Who Participates in Higher Education in India? Rethinking the Role of Affirmative Action," Economic and Political Weekly, Vol xlv no. 39, September.

Chalam, K C. 2007. Caste Based Reservations and Human Development in India, Sage Publication, New Delhi.

Government of India. 2002-07. "Tenth, Eleventh and Twelfth Five Year Plan Document,“ Planning Commission, Vol. 2, Chapter 4.1: 5-8.

Government of India. 2006. "Recommendations of the National Knowledge Commission," A High Level Advisory Body to the Prime Minister of India, Chaired by Sam Pitroda.

Government of India. 2007. "Draft Report of Working Group on Higher Education for the XI Plan," The Planning Commission, New Delhi.

Hanna, Rema, and Leigh Linden. 2009. "Measuring Discrimination in Education," NBER Working Paper 15057, Cambridge, MA.

Kaul, Sanat. 2006. "Higher education in India: Seizing the Opportunity," ICRIER Working paper No. 179, May. 
NCERT [National Council of Educational Research and Training]. 1998. Sixth All India Educational Survey. New Delhi.

Pridmore, P. 2007. "The Impact of Health on Education Access and Attainment: A CrossNational Review of the Research Evidence." CREATE Pathways to Access Research Monograph No 2., CREATE and Institute of Education, University of London.

PROBE. 1999. Public Report on Basic Education in India. Oxford University Press, New Delhi.

Sedwal. Mona, and Sangeeta Kamat. 2008. "Education and social equity with a special focus on Scheduled Castes and Scheduled Tribes in elementary education," Create Pathways to Access, Research Monograph No. 19, NUEPA, May.

\footnotetext{
${ }^{\mathrm{i}}$ This flagship program of the government of India towards achievement of universal elementary education is being implemented in partnership with the state governments throughout the country.
} 